\title{
Environmental Integrants Affecting the Spreadability of SARS-CoV-12
}

\author{
Muhammad Torequl Islam ${ }^{1}[$
}

Received: 8 June 2020 / Accepted: 23 June 2020 / Published online: 28 July 2020

(c) Springer Science+Business Media, LLC, part of Springer Nature 2020

\section{To the Editor,}

The outbreak of a novel severe acute respiratory syndrome coronavirus 2019 (SARS-CoV-2 also called nCoV-19) has affected millions of people and caused thousands of deaths around the world. The human coronaviruses, especially the SARS-CoVs depend on some environmental factors that affects the spreadability and pathogenesis of these kinds of life-threatening viruses. In this letter, a current scenario has been drawn on the environmental components that affects the spreadability of SARS-CoV-2. It has been found that the SARS-CoV-2 depends on the temperature, humidity, $\mathrm{pH}$, sunlight, air pollution, water contamination, minerals on earth, and surface state (e.g., solid or liquid) to spread and survive. This paper might be helpful to understand the physical and morphological patterns of the SARS-CoV-2, which may help us to control this pandemic outbreak.

Only a single cough can produce up to 3000 droplets with which the SARS-CoV-2 may spread from the infected person to the other persons. They may remain in the air, land on other people, clothing and surfaces around them. The SARS-CoV-2 is evident to survive and remain infectious for up to 3 days on hard surfaces (e.g., plastic, stainless steel) at $21-25^{\circ} \mathrm{C}$ (40-50\% relative humidity) (Chan et al. 2011). If left untreated, it can survive on metal, glass and plastic up to 9 days. It has been also reported that SARS-CoV-2 can survive for more than 28 days at $4{ }^{\circ} \mathrm{C}$ (BBC Future 2020a). However, higher temperature and humidity, high or low $\mathrm{pH}$, oxidants present in air or water, earth minerals and sunlight all facilitate virus reduction (WHO \& UNICEF 2020). For an example, the viability of SARS-CoVs loses rapidly at higher temperatures (e.g., $38^{\circ} \mathrm{C}$ ) and higher relative humidity (e.g., > 95\%) (Chan et al. 2011). $100^{\circ} \mathrm{C}$ with an inlet $\mathrm{CO}_{2}$ pressure kills virus particles effectively. $56{ }^{\circ} \mathrm{C}$ is evident to

Muhammad Torequl Islam

dmt.islam@bsmrstu.edu.bd

1 Department of Pharmacy, Life Science Faculty, Bangabandhu Sheikh Mujibur Rahman Science and Technology University, Gopalganj 8100, Bangladesh kill about 10,000 viral particles within 15 min (Lai et al. 2005). Therefore, the stem inhalation during the novel coronavirus disease 2019 (COVID-19) may work through this way. The SARS-CoV-2 can be inactivated completely using common fixatives used in laboratory, ultraviolet light, alkaline $(\mathrm{pH}>12)$ or acidic $(\mathrm{pH}<3)$ conditions (Darnell et al. 2004). The virus is stable for 3 weeks at room temperature (20 to $25^{\circ} \mathrm{C}$ or 68 to $77^{\circ} \mathrm{F}$ ) in a liquid environment. It spreads rapidly in cities and regions of the world where average temperatures have been around $5-11^{\circ} \mathrm{C}\left(41-52^{\circ} \mathrm{F}\right)$ and relative humidity has been low.

Among the environmental integrants, air is playing a pivotal role to spread this virus from one person to the others. Air pollution causes weakening our immune system, reduces the ability to fight against infectious agents. Suspended particles may carry the virus particles that remain in the air. A correlation between the COVID-19 mortality rates and high levels of air pollution has been seen in Italy and USA. A small increases in fine particulate matter (e.g., PM2.5) have been found to increase the SARS-CoV-2 transmission. For example, an increase of just one microgram per cubic metre corresponded to a $15 \%$ increase in COVID-19 deaths (BBC Future 2020b). Recently, the WHO has declared the SARS-CoV-2 as an airborne virus.

Water either transmits the CoVs in human still remains controversial. The SARS-CoVs can survive in water and remain infectious for long periods (days to weeks), therefore, these may affect people and other animals if aerosols are generated (Casanova et al. 2009; Gundy et al. 2009). It has been demonstrated that SARS-CoVs have low stability in the environment, very sensitive to oxidants (e.g., chlorine) and are inactivated significantly faster in water. However, SARS-CoV-2 has been found in the fecal samples and anal swabs of some patients, therefore, there is a possibility of fecal-oral (including waterborne) transmission of this virus (Rosa et al. 2020). Moreover, nCoV-19 is evident to infect human small intestinal enterocytes (Zang et al. 2020) and has been demonstrated to be found on the human ocular surface (Zhou et al. 2020). 
The natural adsorbents, including clay, charcoal, and clay minerals showed $99.99 \%$ adsorption of SARS-CoV-2 (Robson 2020). The minerals may act against SARS-CoV-2, including selenium (Hiffler and Rakotoambinina 2020) and zinc (Skalny et al. 2020). In contrary, iron-containing enzymes are essential for the viruses, including SARS$\mathrm{CoV}-2$ to complete their replication process. Therefore, iron chelation therapy might be an alternative option for the COVID-19 patients (Liu et al. 2020). Moreover, medicinal plants or their derivatives are also evident to act against SARS-CoV-2 (Aanouz et al. 2020; Islam et al. 2020).

It is clear that, to date, we do not have even a single remedy for SARS-CoV-2 infection. However, along with the other preventive measures if we can manage the abovementioned environmental constraints properly, it should be possible to fight against the pandemic COVID-19. Additionally, it is also necessary to study all the environmental components that affecting the survival, replication, spreadability or transmission and pathogenicity of SARS-CoV-2 in human and other animals.

\section{Compliance with Ethical Standards}

Conflict of interest The author declare that have no conflict of interest.

\section{References}

Aanouz, I., Belhassan, A., El Khatabi, K., Lakhlifi, T., El Idrissi, M., \& Bouachrine, M. (2020). Moroccan medicinal plants as inhibitors of COVID-19: Computational investigations. Journal of Biomolecular Structure and Dynamics. https://doi.org/10.1080/07391 102.2020.1758790.

BBC Future. (2020a). Will warm weather really kill off Covid-19? Retrieved from https://www.bbc.com/future/article/20200323coronavirus-will-hot-weather-kill-covid-19

BBC Future. (2020b). How air pollution exacerbates Covid-19. Retrieved from https://www.bbc.com/future/article/20200 427-how-air-pollution-exacerbates-covid-19

Casanova, L., Rutala, W. A., Weber, D. J., \& Sobsey, M. D. (2009). Survival of surrogate coronaviruses in water. Water Research, 43(7), 1893-1898. https://doi.org/10.1016/j.watres.2009.02.002.

Chan, K. H., Peiris, J. S. M., Lam, S. Y., Poon, L. L. M., Yuen, K. Y., \& Seto, W. H. (2011). The effects of temperature and relative humidity on the viability of the SARS coronavirus. Archives of Virology, 2011, 7. https://doi.org/10.1155/2011/734690.

Darnell, M. E. R., Subbarao, K., Feinstone, S. M., \& Taylor, D. R. (2004). Inactivation of the coronavirus that induces severe acute respiratory syndrome, SARS-CoV. Journal of Virological Methods, 121(1), 85-91. https://doi.org/10.1016/j.jviro met.2004.06.006.

Gundy, P. M., Gerba, C. P., \& Pepper, I. L. (2009). Survival of coronaviruses in water and wastewater. Food and Environmental Virology, 1(1), 10. https://doi.org/10.1007/s12560-008-9001-6.

Hiffler, L., \& Rakotoambinina, B. (2020). Selenium and RNA virus interactions: Potential implications for SARS-CoV-2 infection (COVID-19). SSRN. https://doi.org/10.2139/ssrn.3594240.

Islam, M. T., Sarkar, C., El-Kersh, D. M., Jamaddar, S., Uddin, S. J., Shilpi, J. A., et al. (2020). Natural products and their derivatives against coronavirus: A review of the non-clinical and pre-clinical data. Phytotherapy Research. https://doi.org/10.1002/ptr.6700.

Lai, M. Y., Cheng, P. K., \& Lim, W. W. (2005). Survival of severe acute respiratory syndrome coronavirus. Clinical Infectious Diseases, 41(7), e67-71. https://doi.org/10.1086/433186.

Liu, W., Zhang, S., Nekhai, S., \& Liu, S. (2020). Depriving iron supply to the virus represents a promising adjuvant therapeutic against viral survival. Current Clinical Microbiology Reports. https://doi. org/10.1007/s40588-020-00140-w.

Robson, B. (2020). Computers and viral diseases. Preliminary bioinformatics studies on the design of a synthetic vaccine and a preventative peptidomimetic antagonist against the SARS-CoV-2 (2019-nCoV, COVID-19) coronavirus. Computers in Biology and Medicine, 119, 103670. https://doi.org/10.1016/j.compbiomed .2020.103670.

Rosa, G. L., Bonadonna, L., Lucentini, L., Kenmoe, S., \& Suffredini, E. (2020). Coronavirus in water environments: Occurrence, persistence and concentration methods-A scoping review. Water Research, 179, 115899. https://doi.org/10.1016/j.watre s.2020.115899.

Skalny, A. V., Rink, L., Ajsuvakova, O. P., Aschner, M., Gritsenko, V. A., Alekseenko, S. I., et al. (2020). Zinc and respiratory tract infections: Perspectives for COVID-19 (Review). International Journal of Molecular Medicine, 46, 17-26.

WHO \& UNICEF (2020) Water, sanitation, hygiene, and waste management for the COVID-19 virus. Interim guidance. Retrieved from https://www.who.int/publications/i/item/water-sanitation -hygiene-and-waste-management-for-the-covid-19-virus-inter im-guidance

Zang, R., Castro, M. F. G., McCune, B. T., Zeng, Q., Rothlauf, P. W., Sonnek, N. M., et al. (2020). TMPRSS2 and TMPRSS4 promote SARS-CoV-2 infection of human small intestinal enterocytes. Science Immunology, 5(47), eabc3582. https://doi.org/10.1126/sciim munol.abc3582.

Zhou, L., Xu, Z., Castiglione, G. M., Soiberman, U. S., Eberhart, C. G., \& Duh, E. J. (2020). ACE2 and TMPRSS2 are expressed on the human ocular surface, suggesting susceptibility to SARS-CoV-2 infection. bioRxiv. https://doi.org/10.1101/2020.05.09.086165.

Publisher's Note Springer Nature remains neutral with regard to jurisdictional claims in published maps and institutional affiliations. 